\title{
Incidence Rates of Malignant Diseases in Childhood and Adolescence in Children to Swedish Fishermen
} Ann Charlotte Dreifaldt ${ }^{1}$, Michael Carlberg ${ }^{1}$ and Lennart Hardell ${ }^{1, *}$

${ }^{1}$ Department of Oncology, Örebro University Hospital, S-701 85 Örebro, Sweden

\begin{abstract}
In this register-based study the risks of childhood malignant diseases in the offspring of Swedish fishermen were analysed. Having a fisherman as a parent was used as surrogate for exposure, both pre- and postnatal, to Persistent Organic Pollutants (POPs) due to high fish consumption. A cohort of fishermen was identified by Statistics Sweden by using the national census registration carried out from 1960 to 1990 . For each fisherman, 4 matched - population-based referents were drawn. The children of fishermen and referents were identified and matched against the Swedish cancer registry 1960-1998, the causes of death registry 1960-1997 and notifications of deaths 1998-1999. Children diagnosed with cancer before the parent appeared in the census were excluded. MantelHaenszel analysis, adjusted for age and gender, was performed. Incidence rate ratios (IRR) and 95\% Confidence Intervals $(\mathrm{Cl})$ for the different malignant diagnoses in children 0 to 19 years old were calculated. Fishermen children had an overall increased incidence rate ratio of cancer, $I R R=1.38,95 \% \mathrm{Cl}=0.96-2.00$. An increased incidence rate ratio was observed for acute lymphatic leukaemia (ALL), IRR=2.65, 95\% Cl=1.005-6.97, and in west coast children for non-Hodgkin's lymphoma, IRR=3.19, $95 \% \mathrm{Cl}=0.98-10.4$. The importance of exposure to POPs to these findings needs further investigation.
\end{abstract}

Keywords: Child; Case-control; Cancer; Leukaemia; Non-Hodgkin's lymphoma; Sweden; Fisherman; Birth weight

\section{Introduction}

Persistent organic pollutants (POPs) include lipophilic halogenated organics, such as dioxins, polychlorinated biphenyls (PCBs), chlorinated pesticides, and polybrominated flame-retardants; and perfluorinated compounds used as repellents. These compounds tend to bioaccumulate within the food chain and may cause a variety of adverse health effects, including cancer, immune system suppression, decrements in cognitive and neurobehavioral function, disruption of sex steroid and thyroid function, and some of them increase the risk of chronic diseases, such as hypertension, cardiovascular disease, and diabetes [1].

Regarding PCBs, there is cancer risk for global consumers via consumption of aquatic products, especially marine fish, based on cancer and noncancerous hazard ratio assessment [2]. Analyzed fish from Alaska showed significant concentrations of POPs, in particular of PCBs. For cancer health endpoints for PCBs, all analysed species would trigger strict advisories of between two and six meals per year, depending upon species. For noncancerous effects by PCBs, advisories of between seven and twenty-two meals per year were triggered, which raises the question whether these fishes are safe to eat, particularly for sensitive populations [3].

Children are exposed to POPs both during their foetal life and in early childhood that is of concern since this exposure might have an impact on children's health. Reduced birth weight, hyper pigmentation and later on lower scores in developmental and cognitive test were seen in children born to women accidentally exposed to PCBs and dibenzofurans in Taiwan in 1979 (the Yucheng incident) [4]. In Sweden, low birth weight has also been associated with the mother's high dietary intake of fish contaminated with persistent organochlorine compounds [5,6]. Previously, prenatal exposure to PCBs, evaluated in cord blood, has been associated with lower weight at the age of four [7]. Attenuated growth of breast-fed children exposed to increased concentrations of methylmercury and PCBs was observed in a cohort of children from the Faeroe Islands [8]. Negative associations between PCBs in breast milk and children's mental and motor development was seen in German children [9]. Intellectual impairment in children to mothers with a high consumption of fish from Lake Michigan was associated with high PCB exposition in utero [10].

Children are exposed to POPs both during their foetal life and through breast-feeding [11]. PCBs, polybrominated diphenyl ethers (PBDEs) and pentachlorophenols (PCPs) were present in maternal blood plasma and transferred to cord blood plasma and breast milk in healthy women from Stockholm. The highest PCB levels were found in the mother consuming fatty fish most frequently $[12,13]$. Presence of contaminants in breast milk is worrying, and in the beginning of the 1970's high levels of DDT compounds, PCBs and polychlorinated naphtalenes (PCNs) were observed. These levels have now decreased but instead levels of PBDEs in Swedish human milk have increased from 1972 to 1997 [14]. In a previous study we looked at the duration of breast-feeding and the risk of malignant diseases in childhood and found no association except for a statistically significant increased odds ratio for Non-Hodgkin's lymphoma, although this was based on low numbers [15].

A childhood population expected to be more exposed to POPs is children of fishermen. Fish accumulates pollutants in water which then bio-accumulate in fatty tissues, both in the fish and in their consumers

*Corresponding authors: Lennart Hardell, MD, PhD, Department of Oncology, Örebro University Hospital, S-701 85 Örebro, Sweden, Tel:+46 1960210 00; Fax: +4619 1017 68; E-mail: lennart.hardell@orebroll.se

Received October 30, 2013; Accepted November 24, 2013; Published November 29, 2013

Citation: Dreifaldt AC, Carlberg M, Hardell L (2013) Incidence Rates of Malignant Diseases in Childhood and Adolescence in Children to Swedish Fishermen. J Carcinog Mutagen 5: 153. doi:10.4172/2157-2518.1000153

Copyright: (c) 2013 Dreifaldt AC, et al. This is an open-access article distributed under the terms of the Creative Commons Attribution License, which permits unrestricted use, distribution, and reproduction in any medium, provided the original author and source are credited. 
[16]. Swedish fishermen and their wives have a higher intake of fish compared to the general population $[5,17,18]$. High consumption of fish correlated with higher plasma levels of certain PCB congeners, $p, p^{\prime}$ DDT and p,p'-DDE in Swedish men [19]. Fishermen from the Swedish east coast were shown to have higher levels of PCBs, Polychlorinated Dibenzo p-Dioxins (PCDDs) and furans (PCDFs) than both west coast fishermen and their referents due to higher consumption of fatty fish [18].

The aim of this study was to investigate the risk of malignant diseases in children of Swedish fishermen since we can assume that their children are more exposed to POPs than children from the general population. We particularly looked at the risk of malignant diseases in childhood and adolescence, i.e. aged 0-19 years at the time of diagnosis.

\section{Materials and Methods}

This study is register-based. A cohort of fishermen was identified by Statistics Sweden using the national census registration. The national population and housing registration has been carried out in 1960, 1970, 1975, 1980, 1985 and 1990 and contains several individual registration parameters. We selected the individuals having occupation as fisherman, their identification number, socio-economic (SEI) code, residence code, wife's or husband's id-number and occupation. Information on children, their id-number, sex and birth date was collected. For each fisherman, 4 population-based referents were drawn from the census. The referents were matched for sex, age within 5-year strata, SEI-code and population density. Population density was divided into 11 groups, with lowest population number $<199$ persons and highest $>100,000$ persons. The referents were population based from the entire country, not only local. For the 1975 census SEI-code was missing and for 1985 population density area was missing. Referents to fishermen first appearing in either census 1975 or 1985 were selected from the 1980 census. From the 1960 census the fourth referent was missing for 91 fishermen, from the 1980 census 4 fishermen did not have the third and fourth referent since they did not meet the inclusion criteria. The children of referents were also identified; see Table 1 for numbers from the different census.

The data files were matched against the Swedish Cancer Registry for the time period 1960 to 1998 , the causes of death registry 1960 to 1997 and notifications of deaths 1998 to 1999. The Swedish Cancer Registry started in 1958 and reporting to the registry is compulsory. We excluded children older than 19 years at the parents' entry in the census or with a cancer diagnosis before the parent (fisherman or referent) was included into the census and also those born after 1998. Information from the Swedish Medical Birth Register was obtained for mothers and children from 1973 and onward. The register contains information on the mother's reproductive history, factors concerning pregnancy and information on the newborn child. From Statistics Sweden, information of the average school proficiency grade on a 5 level scale that the children received in ninth grade (at 15 years) was also obtained. This information existed for children born 1969 to 1982. The register processing was done by Statistics Sweden.

In the present study we selected children and adolescents of fishermen and analysed their risk of malignant diseases in the age period 0 to 19 years compared with children of fishermen's referents. From the Cancer Registry information on site code (ICD-7) and histology code was obtained. The cancer cases were grouped according to the International Classification of Childhood Cancer (ICCC) [20]. In the analysis we also divided the fishermen into two main groups, west and east coast fishermen. The west coast fishermen were residing in counties on the west coast in Sweden by the fishing waters of Kattegatt and Skagerrak. The east coast fishermen resided in counties along the Baltic and Bothnia Sea, classed as a "closed" sea due to lower water exchange with the oceans. Furthermore, the contamination with POPs in fish differs between the west coast and east coast.

A smaller group consisted of the Swedish inland fishermen who are mainly fishing in great lakes. The children of inland fishermen $(n=667)$ were few, no one was diagnosed with a malignant disease thus their results are not presented separately. As background information, we assessed information from the Swedish Medical Birth Register such as birth weight, birth length, weeks of pregnancy at birth and head circumference at birth for all children and separately for east and west coast fishermen children compared to referent children. These data were available only for children born during the years 1973 to 1999 since the registry was established in 1973.

\section{Statistical methods}

The incidence rates of all malignant diseases combined as well as for the separate ICCC diagnoses were calculated using the number of cases identified and by calculating the person years the fishermen children and the referent children contributed. Calculation of number of person years started at the year of inclusion of the parent in the census, or the birth year of the child (if later than census year). The number of person

\begin{tabular}{|c|c|c|c|c|c|c|}
\hline & \multicolumn{2}{|c|}{ Number of fishermen/referents } & \multicolumn{2}{|c|}{ Number of children, fishermen/referents } & \multicolumn{2}{|c|}{$\begin{array}{l}\text { Number of children with cancer, fishermen } \\
\text { referents }\end{array}$} \\
\hline & Fishermen & Referents & Children, fishermen & Children, referents & Children, fishermen & Children, referents \\
\hline \multicolumn{7}{|c|}{ Census } \\
\hline Census 60 & 8,979 & 35,825 & 13,613 & 52,644 & 24 & 59 \\
\hline Census 70 & 1,624 & 6,496 & 2,876 & 11,700 & 5 & 19 \\
\hline Census 80 & 1,840 & 7,320 & 3,377 & 13,351 & 6 & 21 \\
\hline Census 85 & 983 & 3,932 & 1,715 & 6,515 & 2 & 5 \\
\hline Census 90 & 513 & 2,052 & 714 & 2,852 & 2 & 3 \\
\hline \multicolumn{7}{|c|}{ Regions } \\
\hline West coast & 6,381 & 4,160 & 10,858 & 6,223 & 25 & 4 \\
\hline East coast & 7,040 & 30,514 & 10,765 & 49,642 & 14 & 60 \\
\hline Inland & 517 & 20,944 & 667 & 31,192 & 0 & 43 \\
\hline No information & 1 & 7 & 5 & 5 & 0 & 0 \\
\hline Total & 13,939 & 55,625 & 22,295 & 87,062 & 39 & 107 \\
\hline Eligible for analysis ${ }^{*}$ & & & 18,614 & 71,796 & 39 & 107 \\
\hline
\end{tabular}

*Diagnosis the same year or after including parent from Census, up to $19 \mathrm{y}$ and born before 1998

Table 1: Total number of fishermen/referents and children of fishermen/referents in the different census and regions. 
Citation: Dreifaldt AC, Carlberg M, Hardell L (2013) Incidence Rates of Malignant Diseases in Childhood and Adolescence in Children to Swedish Fishermen. J Carcinog Mutagen 5: 153. doi:10.4172/2157-2518.1000153

Page 3 of 7

years was calculated until the year of cancer diagnosis, the year when the child turned twenty years, or until the end of the study period (1998). The incidence rate ratios (IRR) and 95\% confidence intervals (CI) for all childhood malignant diseases combined and for the different ICCC diagnoses in children of fishermen compared to children of referents were calculated using Mantel-Haenszel analysis, adjusted for age and gender using the incidence rate of the referent children as reference value. We adjusted for age and gender since the initial matching to identify fishermen and referents was done on the parents and not on the children and since childhood cancer incidence may differ between age groups and boys and girls. We looked separately at the incidence rate ratios of east and west coast fishermen children compared to all referent children. For analysis of data from the Swedish Medical Birth Register shown in Table 3 and for the average grade obtained at 15 years shown in Table 4, the means of the variable for fishermen children and referents were compared using the Student's t-test. All analyses were done using Stata/SE 8.2 (Stata/SE 8.2 for Windows; StataCorp, College Station, TX, USA).

\section{Results}

In all, 13,939 fishermen and 55,625 referents were identified. The majority of fishermen were men and less than $3 \%$ were women, see Table 1. Total, 22,295 children of fishermen and 87,062 children of referents were identified. Of these, 18,614 fishermen children and 71,796 referent children were eligible for studying the incidence rate ratios of childhood cancer (exclusion criteria, see Material and methods). Of the referent children, $7 \%$ were residing in counties along the west coast of Sweden, 57\% from the east coast and 35\% from the inland. This might be due to the fact that the referent fishermen were matched for population density. The east coast line in Sweden is approximately three times longer than the west coast line with larger areas of lower populated areas than the west coast. The group of all fishermen children generated 216,455 person years (py) during the study period. Of these the west coast fishermen children contributed with 113,663 py, the east coast fishermen children 97,923 py and the referent children 822,351 py. The majority were identified from the 1960 census, see Table 1 . We first analysed the patterns of childhood cancer in the $0-14$ year age group. The cases were few, only 23 children from the fishermen cohort and 66 children from the referent cohort were diagnosed with a malignant disease. With few cases the IRR calculations were not reliable so we included the adolescent cases. In the age group 0 to 19 years, 39 cases of childhood cancer were observed from the fishermen and 107 from the referent families.

For all children of fishermen 0-19 years in Sweden (sea and inland lakes), we found an increased incidence rate ratio for a malignant disease during childhood or adolescence, IRR $=1.38,95 \% \mathrm{CI}=0.96$ 2.00 compared to children of parents with other occupations. For west coast children of fishermen, the excess in incidence rate was statistically significant, IRR $=1.69,95 \% \mathrm{CI}=1.09-2.61$. The number of cases, incidence rates and IRRs for the different ICCC diagnoses for all fishermen children, as well as for fishermen children from the west and east coast regions compared to all referent children are shown in Table 2.

A statistically significant IRR was found for acute lymphatic leukaemia (ALL), $I R R=2.65,95 \% \mathrm{CI}=1.005-6.97$. No ALL cases occurred in daughters of fishermen. An excess in lymphoma incidence rates, especially non-Hodgkin's lymphoma (NHL), IRR=3.19, 95\% $\mathrm{CI}=0.98-10.4$ was seen for west coast fishermen children. No cases of lymphoma occurred in east coast children. For brain (CNS) tumours,

\begin{tabular}{|c|c|c|c|c|}
\hline Diagnosis & $\begin{array}{c}\text { Number of } \\
\text { cases }\end{array}$ & $\begin{array}{c}\text { Incidence per } \\
100,000 \mathrm{py}^{*}\end{array}$ & MH-IRR & $95 \% \mathrm{Cl}$ \\
\hline \multicolumn{5}{|l|}{ All diagnoses } \\
\hline Children of referents & 107 & 13.01 & $(1.00)$ & - \\
\hline Children of fishermen & 39 & 18.02 & 1.38 & $0.96-2.00$ \\
\hline West coast & 25 & 21.99 & 1.69 & $1.09-2.61$ \\
\hline East coast & 14 & 14.30 & 1.10 & $0.63-1.92$ \\
\hline \multicolumn{5}{|l|}{ Leukaemia } \\
\hline Children of referents & 23 & 2.80 & $(1.00)$ & - \\
\hline Children of fishermen & 8 & 3.70 & 1.30 & $0.58-2.92$ \\
\hline West coast & 4 & 3.52 & 1.24 & $0.43-3.58$ \\
\hline East coast & 4 & 4.08 & 1.45 & $0.50-4.20$ \\
\hline \multicolumn{5}{|l|}{ Leukaemia, ALL } \\
\hline Children of referents & 10 & 1.22 & $(1.00)$ & - \\
\hline Children of fishermen & 7 & 3.23 & 2.65 & $1.005-6.97$ \\
\hline West coast & 4 & 3.52 & 2.87 & $0.90-9.17$ \\
\hline East coast & 3 & 3.06 & 2.52 & $0.69-9.16$ \\
\hline \multicolumn{5}{|l|}{ Leukaemia, other } \\
\hline Children of referents & 13 & 1.58 & $(1.00)$ & - \\
\hline Children of fishermen & 1 & 0.46 & 0.28 & $0.04-2.19$ \\
\hline West coast & 0 & 0.00 & - & - \\
\hline East coast & 1 & 1.02 & 0.64 & $0.08-4.90$ \\
\hline \multicolumn{5}{|l|}{ Lymphomas } \\
\hline Children of referents & 18 & 2.19 & $(1.00)$ & - \\
\hline Children of fishermen & 6 & 2.77 & 1.27 & $0.50-3.21$ \\
\hline West coast & 6 & 5.28 & 2.43 & $0.97-6.13$ \\
\hline East coast & 0 & 0.00 & - & - \\
\hline \multicolumn{5}{|c|}{ Lymphomas, Hodgkin's disease } \\
\hline Children of referents & 9 & 1.09 & $(1.00)$ & - \\
\hline Children of fishermen & 2 & 0.92 & 0.86 & $0.19-3.98$ \\
\hline West coast & 2 & 1.76 & 1.66 & $0.36-7.65$ \\
\hline East coast & 0 & 0.00 & - & - \\
\hline \multicolumn{5}{|c|}{ Lymphomas, non-Hodgkin's } \\
\hline Children of referents & 9 & 1.09 & $(1.00)$ & - \\
\hline Children of fishermen & 4 & 1.85 & 1.68 & $0.52-5.44$ \\
\hline West coast & 4 & 3.52 & 3.19 & $0.98-10.4$ \\
\hline East coast & 0 & 0.00 & - & - \\
\hline \multicolumn{5}{|l|}{ CNS tumours, all types } \\
\hline Children of referents & 27 & 3.28 & $(1.00)$ & - \\
\hline Children of fishermen & 6 & 2.77 & 0.84 & $0.35-2.04$ \\
\hline West coast & 5 & 4.40 & 1.33 & $0.51-3.47$ \\
\hline East coast & 1 & 1.02 & 0.31 & $0.04-2.29$ \\
\hline \multicolumn{5}{|c|}{ CNS tumours, malignant } \\
\hline Children of referents & 23 & 2.80 & $(1.00)$ & - \\
\hline Children of fishermen & 6 & 2.77 & 0.99 & $0.40-2.42$ \\
\hline West coast & 5 & 4.40 & 1.56 & $0.59-4.11$ \\
\hline East coast & 1 & 1.02 & 0.36 & $0.05-2.69$ \\
\hline \multicolumn{5}{|l|}{ CNS tumours, benign } \\
\hline Children of referents & 4 & 0.49 & $(1.00)$ & - \\
\hline Children of fishermen & 0 & 0.00 & - & - \\
\hline West coast & 0 & 0.00 & - & - \\
\hline East coast & 0 & 0.00 & - & - \\
\hline \multicolumn{5}{|l|}{ Neuroblastoma } \\
\hline Children of referents & 1 & 0.12 & $(1.00)$ & - \\
\hline Children of fishermen & 1 & 0.46 & 3.64 & $0.23-57.9$ \\
\hline West coast & 1 & 0.88 & 6.88 & $0.42-112$ \\
\hline East coast & 0 & 0.00 & - & - \\
\hline \multicolumn{5}{|l|}{ Retinoblastoma } \\
\hline Children of referents & 1 & 0.12 & $(1.00)$ & - \\
\hline Children of fishermen & 2 & 0.92 & 7.28 & $0.66-80.1$ \\
\hline West coast & 2 & 1.76 & 13.8 & $1.24-153$ \\
\hline
\end{tabular}


Citation: Dreifaldt AC, Carlberg M, Hardell L (2013) Incidence Rates of Malignant Diseases in Childhood and Adolescence in Children to Swedish Fishermen. J Carcinog Mutagen 5: 153. doi:10.4172/2157-2518.1000153

Page 4 of 7

\begin{tabular}{|c|c|c|c|c|}
\hline Diagnosis & $\begin{array}{c}\text { Number of } \\
\text { cases }\end{array}$ & $\begin{array}{c}\text { Incidence per } \\
100,000 \text { py }^{*}\end{array}$ & MH-IRR & $95 \% \mathrm{Cl}$ \\
\hline East coast & 0 & 0.00 & - & - \\
\hline \multicolumn{5}{|l|}{ Renal tumours } \\
\hline Children of referents & 1 & 0.12 & $(1.00)$ & - \\
\hline Children of fishermen & 1 & 0.46 & 3.64 & $0.23-58.2$ \\
\hline West coast & 0 & 0.00 & - & - \\
\hline East coast & 1 & 1.02 & 8.14 & $0.51-130$ \\
\hline \multicolumn{5}{|l|}{ Hepatic tumours } \\
\hline Children of referents & 0 & 0.00 & $(1.00)$ & - \\
\hline Children of fishermen & 1 & 0.46 & - & - \\
\hline West coast & 0 & 0.00 & - & - \\
\hline East coast & 1 & 1.02 & - & - \\
\hline \multicolumn{5}{|l|}{ Malignant bone tumours } \\
\hline Children of referents & 9 & 1.09 & $(1.00)$ & - \\
\hline Children of fishermen & 3 & 1.39 & 1.28 & $0.35-4.73$ \\
\hline West coast & 2 & 1.76 & 1.64 & $0.36-7.58$ \\
\hline East coast & 1 & 1.02 & 0.93 & $0.12-7.38$ \\
\hline \multicolumn{5}{|l|}{ Soft tissue sarcomas } \\
\hline Children of referents & 5 & 0.61 & $(1.00)$ & - \\
\hline Children of fishermen & 2 & 0.92 & 1.48 & $0.29-7.55$ \\
\hline West coast & 1 & 0.88 & 1.39 & $0.17-11.6$ \\
\hline East coast & 1 & 1.02 & 1.66 & $0.19-14.2$ \\
\hline \multicolumn{5}{|c|}{ Germ cell and gonadal tumours } \\
\hline Children of referents & 9 & 1.09 & $(1.00)$ & - \\
\hline Children of fishermen & 1 & 0.46 & 0.43 & $0.05-3.36$ \\
\hline West coast & 0 & 0.00 & - & - \\
\hline East coast & 1 & 1.02 & 0.94 & $0.12-7.39$ \\
\hline \multicolumn{5}{|c|}{ Carcinomas, epithelial neoplasms } \\
\hline Children of referents & 9 & 1.09 & $(1.00)$ & - \\
\hline Children of fishermen & 6 & 2.77 & 2.59 & $0.92-7.27$ \\
\hline West coast & 3 & 2.64 & 2.49 & $0.68-9.19$ \\
\hline East coast & 3 & 3.06 & 2.82 & $0.76-10.4$ \\
\hline \multicolumn{5}{|l|}{ Other and unspecified } \\
\hline Children of referents & 4 & 0.49 & $(1.00)$ & - \\
\hline Children of fishermen & 2 & 0.92 & 1.93 & $0.35-10.5$ \\
\hline West coast & 1 & 0.88 & 1.84 & $0.21-16.3$ \\
\hline East coast & 1 & 1.02 & 2.11 & $0.24-18.9$ \\
\hline
\end{tabular}

*Incidence per 100,000 person years (py) calculated on 822,351 py for referent children, 216,455 py for fishermen children (113,663 py west coast, 97,923 py east coast).

Table 2: Mantel-Haenszel incidence rate ratios (MH-IRR) of fishermen children: All, west coast, east coast versus all referent children. Adjustment was made for age in 5 year intervals $(0-4,5-9,10-14,15-19$ years $)$ and gender.

no difference in incidence rates were seen except for malignant CNS tumours, IRR $=1.56,95 \% \mathrm{CI}=0.59-4.11$ for west coast children. No cases of benign CNS tumours occurred among the fishermen children. Among the more uncommon malignant diagnoses, a statistically significant IRR was found for retinoblastoma in west coast fishermen children, based on low numbers. Increased IRRs, although not statistically significant, were seen for fishermen children compared to referent children for several other diagnoses. The calculations were based on low numbers of affected children and the confidence intervals were broad and imprecise. For some diagnoses, IRRs could not be calculated since no cases occurred among fishermen children.

Birth length, birth weight and head circumference as well as weeks of pregnancy at birth are shown in Table 3. Results are for all children born to Swedish fishermen and not only for those with a malignant diagnosis. Children of west coast fishermen were statistically significantly taller, had a bigger head and were heavier at birth than referent children. No such difference was observed for east coast children. Looking at the average school grade at 15 years shown in

Table 4, the score of the fishermen children was statistically significantly lower than the score of the referent child.

\section{Discussion}

This study is based on register data obtained from several Swedish

\begin{tabular}{|c|c|c|c|c|c|c|}
\hline & Number & Mean & Median & Min & Max & $\mathrm{p}$ \\
\hline \multicolumn{7}{|l|}{ Birth length $(\mathrm{cm})^{*}$} \\
\hline \multicolumn{7}{|l|}{ All } \\
\hline Children of fishermen & 4986 & 50.5 & 51 & 31 & 60 & 0.06 \\
\hline West coast & 2529 & 50.6 & 51 & 33 & 59 & 0.0004 \\
\hline East coast & 2289 & 50.4 & 51 & 31 & 60 & 0.98 \\
\hline Children of referents & 17747 & 50.4 & 51 & 27 & 60 & \\
\hline \multicolumn{7}{|l|}{ Boys } \\
\hline Children of fishermen & 2568 & 50.9 & 51 & 31 & 60 & 0.10 \\
\hline West coast & 1332 & 51.0 & 51 & 33 & 59 & 0.01 \\
\hline East coast & 1158 & 50.9 & 51 & 31 & 60 & 0.97 \\
\hline Children of referents & 9159 & 50.9 & 51 & 30 & 60 & \\
\hline \multicolumn{7}{|l|}{ Girls } \\
\hline Children of fishermen & 2418 & 50.1 & 50 & 33 & 58 & 0.28 \\
\hline West coast & 1197 & 50.2 & 50 & 33 & 56 & 0.02 \\
\hline East coast & 1131 & 50.0 & 50 & 35 & 58 & 0.88 \\
\hline Children of referents & 8588 & 50.0 & 50 & 27 & 60 & \\
\hline \multicolumn{7}{|l|}{ Birth weight (grams) ${ }^{\star *}$} \\
\hline \multicolumn{7}{|l|}{ All } \\
\hline Children of fishermen & 5010 & 3555.7 & 3580 & 665 & 5770 & 0.06 \\
\hline West coast & 2542 & 3582.2 & 3610 & 665 & 5360 & 0.0003 \\
\hline East coast & 2300 & 3533.7 & 3550 & 670 & 5770 & 0.75 \\
\hline Children of referents & 17843 & 3537.9 & 3550 & 405 & 6105 & \\
\hline \multicolumn{7}{|l|}{ Boys } \\
\hline Children of fishermen & 2578 & 3629.9 & 3650 & 670 & 5380 & 0.06 \\
\hline West coast & 1337 & 3653.3 & 3680 & 725 & 5360 & 0.005 \\
\hline East coast & 1163 & 3607.1 & 3620 & 670 & 5380 & 0.92 \\
\hline Children of referents & 9207 & 3605.1 & 3630 & 565 & 6105 & \\
\hline \multicolumn{7}{|l|}{ Girls } \\
\hline Children of fishermen & 2432 & 3477.0 & 3500 & 665 & 5770 & 0.42 \\
\hline West coast & 1205 & 3503.4 & 3550 & 665 & 5240 & 0.03 \\
\hline East coast & 1137 & 3458.8 & 3470 & 890 & 5770 & 0.67 \\
\hline \multirow[t]{2}{*}{ Children of referents } & 8636 & 3466.3 & 3480 & 405 & 5660 & \\
\hline & NUMBER & MEAN & MEDIAN & MIN & MAX & $\mathrm{P}$ \\
\hline \multicolumn{7}{|l|}{ Weeks of pregnancy*** } \\
\hline \multicolumn{7}{|l|}{ All } \\
\hline Children of fishermen & 5017 & 39.4 & 40 & 23 & 45 & 0.06 \\
\hline West coast & 2550 & 39.5 & 40 & 23 & 44 & 0.03 \\
\hline East coast & 2299 & 39.4 & 40 & 24 & 45 & 0.19 \\
\hline children of referents & 17844 & 39.4 & 40 & 23 & 45 & \\
\hline \multicolumn{7}{|l|}{$\begin{array}{l}\text { Head circumference } \\
(\mathbf{c m})^{* * * *}\end{array}$} \\
\hline \multicolumn{7}{|l|}{ All } \\
\hline Children of fishermen & 4915 & 34.8 & 35 & 24 & 43 & $<0.0001$ \\
\hline West coast & 2490 & 35.0 & 35 & 26 & 43 & $<0.0001$ \\
\hline East coast & 2259 & 34.7 & 35 & 24 & 40 & 0.25 \\
\hline Children of referents & 17398 & 34.7 & 35 & 24 & 44 & \\
\hline \multicolumn{7}{|l|}{ Boys } \\
\hline Children of fishermen & 2532 & 35.1 & 35 & 25 & 40 & 0.0002 \\
\hline West coast & 1312 & 35.3 & 35 & 26 & 40 & $<0.0001$ \\
\hline East coast & 1142 & 35.0 & 35 & 27 & 40 & 0.63 \\
\hline children of referents & 8978 & 35.0 & 35 & 24 & 43 & \\
\hline Girls & & & & & & \\
\hline
\end{tabular}




\begin{tabular}{|c|c|c|c|c|c|c|}
\hline Children of fishermen & 2383 & 34.5 & 35 & 24 & 43 & 0.01 \\
\hline West coast & 1178 & 34.6 & 35 & 26 & 43 & $<0.0001$ \\
\hline East coast & 1117 & 34.3 & 34 & 24 & 39 & 0.35 \\
\hline Children of referents & 8420 & 34.4 & 34 & 24 & 44 & \\
\hline
\end{tabular}

"Information is missing for 38 children of fishermen, 152 children of referents. "Information is missing for 14 children of fishermen, 56 children of referents. "It*nformation is missing for 7 children of fishermen, 55 children of referents.

****Information is missing for 106 children of fishermen, 473 children of referents. Invalid data ( $<24 \mathrm{~cm}$ or $>44 \mathrm{~cm}$ ) for 3 children of fishermen, 28 children of referents.

Table 3: Birth length, birth weight, weeks of pregnancy and head circumference for children of fishermen and children of referents born 1973-1999. Student's t-test was used to compare children of fishermen (total, west coast and east coast) with children of referents.

\begin{tabular}{|c|c|c|c|c|c|c|}
\hline Average school grade (0-5) & Number & Mean & Median & Min & Max & p \\
\hline All & & & & & & \\
\hline Children of fishermen & 1,776 & 3.06 & 3.10 & 0 & 4.8 & $<0.0001$ \\
\hline West coast & 1,000 & 3.08 & 3.10 & 0 & 4.8 & 0.0007 \\
\hline East coast & 753 & 3.04 & 3.10 & 0 & 4.8 & $<0.0001$ \\
\hline Children of referents & 6,452 & 3.16 & 3.20 & 0 & 4.9 & \\
\hline \multicolumn{7}{|c|}{ Boys } \\
\hline Children of fishermen & 909 & 2.89 & 2.90 & 0 & 4.6 & 0.0003 \\
\hline West coast & 517 & 2.90 & 2.90 & 0 & 4.6 & 0.01 \\
\hline East coast & 383 & 2.86 & 2.90 & 0 & 4.6 & 0.003 \\
\hline Children of referents & 3,337 & 2.98 & 3.00 & 0 & 4.9 & \\
\hline \multicolumn{7}{|c|}{ Girls } \\
\hline Children of fishermen & 867 & 3.24 & 3.30 & 1.2 & 4.8 & $<0.0001$ \\
\hline West coast & 483 & 3.27 & 3.30 & 1.6 & 4.8 & 0.01 \\
\hline East coast & 370 & 3.21 & 3.20 & 1.2 & 4.8 & 0.0001 \\
\hline Children of referents & 3,115 & 3.35 & 3.40 & 0 & 4.9 & \\
\hline
\end{tabular}

Table 4: Average school grade for children of fishermen and children of controls born 1969-1982. Student's t-test was used to compare children of fishermen (total, west coast and east coast) with children of referents.

registers from both Statistics Sweden and the Swedish National Board of Health and Welfare. Every person in Sweden has a unique individual personal identity number enabling easy co-ordination of the registers. The Swedish registers are of good quality and they are based on the entire population. Cancer registration is compulsory and regulated by law. Thus information parameters obtained for both fishermen and referent children were of the same quality and not biased. An increased incidence rate ratio of malignant diseases in children and adolescents to Swedish fishermen compared to referents was found.

Since childhood malignant diseases are rare with an average incidence in Sweden of 16.19 cases/100,000 children and year, the power of the study might be a problem in evaluating results [21] With the size of our material, the power, at $5 \%$ significance level, was $97.6 \%$ for detecting a IRR of $2.0,59.8 \%$ for detecting a IRR of 1.5 and $22.2 \%$ for detecting a IRR of 1.25 for all diagnoses combined [22]. For the different ICCC diagnoses the power of detecting differences was lower due to few cases in each group.

Increased IRR was found for ALL for all fishermen children and for lymphomas, especially non-Hodgkin's, in west coast fishermen children. In a previous Swedish study, an enhanced risk of childhood ALL was found in population centres, but there was no indication that specific geographically localized areas were involved [23]. Another Swedish study on parental occupation and childhood cancer using information from the 1960 national census for occupation, showed an increased risk for lymphoma in children to seamen but no increased risk of cancer for fishermen children. [24].

Since our study was register-based, the exposure assessment to
POPs is quite coarse and other environmental factors could be of importance. In a study of childhood leukaemia clusters in Britain, an increased risk was found for locations close to oil installations [25]. For the leukaemia cases that occurred in our study, year of diagnosis and residential area code was checked. No space or time clustering effect was seen. We also checked if we could find any regional differences in incidence rates of all cancer, and separately for leukaemia, lymphoma or brain tumours. We compared the incidence rates of these diseases for all children (children of fishermen and children of referents) of the coastal regions (east and west coast separately and together) with the incidence rates of the inland children (from fishermen and referent families). The only statistically significant finding was an increased IRR for lymphoma in children of fishermen and referents from the west coast, $\mathrm{IRR}=2.97,95 \% \mathrm{CI}=1.07-8.24$.

Exposure to pesticides has been associated with both childhood ALL and NHL [26-29]. In adults, both pesticides and organic pollutants such as PCBs and dioxins have been shown to increase the risk of NHL [30]. Organochlorines have been shown to be immunotoxic, especially in animal studies. 2,3,7,8-tetrachlorodibenzo- $p$-dioxin (TCDD) has been shown to be a potent immunosuppressant, and different commercial PCB mixtures have immunotoxic effects [31,32]. In a study on men from southeast Sweden, high consumption of fatty fish from the Baltic Sea was correlated with lower proportion of natural killer cells, a subpopulation of lymphocytes [33]. In a Canadian study, cord blood from children from a remote maritime population and from an urban population was collected for organochlorine analysis and for in vitro assessment of cord mononuclear cell activation and cytokine production. Concentrations of organochlorines were significantly higher in the subsistence fishing group. In vitro secretion of tumour necrosis factor-alpha correlated inversely with organochlorine concentration [34]

In a Swedish study of PCBs in plasma of wives to fishermen from the Swedish east coast with a child born between 1973 and 1991, it was noticed that the range of the sum of PCBs in the Swedish women was similar to the levels measured in women who consumed fish from Lake Michigan [35]. No analysis exists for west coast fishermen wives to our knowledge. In dietary interviews performed in the beginning of 1990's, west coast fishermen wives reported a significantly higher consumption of lean fish and shellfish than east coast fishermen wives, whereas their consumption of fatty fish did not differ. The two groups reported higher fish consumption than their referents [5]. Measures of dioxin toxic equivalents (in pg WHO-TEQ/g fresh weight) in fish were done in 2001 by the Swedish National Food Administration. It shows that herring, from the mid part of the eastern coastline, had a dioxin content ranging from 10 to $23 \mathrm{pg}$ WHO-TEQ/g fresh weight. Crabs fished on the west coast contained 0.85 to $13 \mathrm{pg}$ WHO-TEQ/g fresh weight depending on which part that was analysed. Analyses of concentrations of dioxins and PCBs in Swedish food have been updated for the time period 2000-2011 [36]. The concentrations in fat fish from the Baltic sea are still high and exceed current guidelines. There are now certain time trends for changing concentrations.

Intellectual impairment has been reported in children born to mothers with a high consumption of fish from Lake Michigan contaminated with PCBs [10]. In this study we saw that Swedish fishermen children had statistically significantly lower grades in school at age 15 than referent children. However, we cannot conclude from this study that this finding is due to environmental contaminants.

Previously, another Swedish group reported decreased birth weight in infants born to wives and sisters of east coast fishermen compared 
Citation: Dreifaldt AC, Carlberg M, Hardell L (2013) Incidence Rates of Malignant Diseases in Childhood and Adolescence in Children to Swedish Fishermen. J Carcinog Mutagen 5: 153. doi:10.4172/2157-2518.1000153

to children born to women from west coast fishermen families [5,6]. In our study, east coast fishermen children's birth weight did not differ from the referents and west coast fishermen children were statistically significantly heavier at birth than control children. A possible explanation to this finding is that the referents selected in our study by Statistics Sweden were in majority from the east coast. We probably found different results than the other authors since we used different referents.

The reason for the increased risk of childhood malignant diseases observed in this study is unclear. The eventual role of organic pollutants in the aetiology in childhood leukaemia and non-Hodgkin's lymphoma as well as the underlying mechanisms needs to be further investigated. One option would be measurements of certain POPs in parents to children with a malignant disease as well as in the child comparing the results with a reference population.

It should however be noted that the concentration decreased for all POPs in the Swedish population during 1993-2007 [37]. The annual change was statistically significant for the sum of PCBs $-7.2 \%, \mathrm{HCB}$ $-8.8 \%$, DDE- $13.5 \%$ and the sum of chlordanes $-10.3 \%$. BMI and age were determinants of the concentrations. Cumulative breast-feeding $>8$ months gave statistically significantly lower concentrations for the sum of PCBs, DDE and the sum of chlordanes. Parity with $>2$ children yielded statistically significantly lower sum of PCBs. All the studied POPs decreased during the time period, probably due to restrictions of their use. However, as noted above high concentrations are still found in fat fish from the Baltic sea [36].

\section{Acknowledgment of Financial Support}

The study was supported by grants from Cancer och Allergifonden, the Örebro County Council Foundation and from Nyckelfonden, Örebro University Hospital.

\section{References}

1. Carpenter DO (2011) Health effects of persistent organic pollutants: the challenge for the Pacific Basin and for the world. Rev Environ Health 26: 61-69.

2. Yu HY, Guo Y, Zeng EY (2010) Dietary intake of persistent organic pollutants and potential health risks via consumption of global aquatic products. Environ Toxicol Chem 29: 2135-2142.

3. Hardell S, Tilander H, Welfinger-Smith G, Burger J, Carpenter DO (2010) Levels of polychlorinated biphenyls (PCBs) and three organochlorine pesticides in fish from the Aleutian Islands of Alaska. PLoS One 5: e12396.

4. Rogan WJ, Gladen BC, Hung KL, Koong SL, Shih LY, et al. (1988) Congenital poisoning by polychlorinated biphenyls and their contaminants in Taiwan. Science 241: 334-336.

5. Rylander L, Strömberg U, Hagmar L (1995) Decreased birthweight among infants born to women with a high dietary intake of fish contaminated with persistent organochlorine compounds. Scand J Work Environ Health 21: 368375 .

6. Rylander L, Strömberg U, Hagmar L (2000) Lowered birth weight among infants born to women with a high intake of fish contaminated with persistent organochlorine compounds. Chemosphere 40: 1255-1262.

7. Jacobson JL, Jacobson SW, Humphrey HE (1990) Effects of exposure to PCBs and related compounds on growth and activity in children. Neurotoxicol Teratol 12: 319-326.

8. Grandjean P, Budtz-Jørgensen E, Steuerwald U, Heinzow B, Needham LL, et al. (2003) Attenuated growth of breast-fed children exposed to increased concentrations of methylmercury and polychlorinated biphenyls. FASEB $\mathrm{J} 17$ : 699-701.

9. Walkowiak J, Wiener JA, Fastabend A, Heinzow B, Krämer U, et al. (2001) Environmental exposure to polychlorinated biphenyls and quality of the home environment: effects on psychodevelopment in early childhood. Lancet 358 1602-1607.

10. Jacobson JL, Jacobson SW (1996) Intellectual impairment in children exposed to polychlorinated biphenyls in utero. $\mathrm{N}$ Engl J Med 335: 783-789.
11. Ribas-Fitó N, Grimalt JO, Marco E, Sala M, Mazón C, et al. (2005) Breastfeeding and concentrations of HCB and p,p'-DDE at the age of 1 year. Environ Res 98 8-13.

12. Meironyté Guvenius D, Aronsson A, Ekman-Ordeberg G, Bergman A Noren K (2003) Human prenatal and postnatal exposure to polybrominated diphenyl ethers, polychlorinated biphenyls, polychlorobiphenylols, and pentachlorophenol. Environ Health Perspect 111: 1235-1241.

13. Meironyté D, Norén K, Bergman A (1999) Analysis of polybrominated dipheny ethers in Swedish human milk. A time-related trend study, 1972-1997. J Toxicol Environ Health A 58: 329-341.

14. Norén K, Meironyté D (1998) Contaminats in Swedish human milk. Decreasing levels of organochlorine and increasing levels of organobromine compounds. In: Johansson N, Naturvårdsverket, (eds.) Organohalogen compounds, 38 Stockholm: Swedish Environmental Protection Agency Naturvårdsverket, 1-4.

15. Hardell L, Dreifaldt AC (2001) Breast-feeding duration and the risk of malignant diseases in childhood in Sweden. Eur J Clin Nutr 55: 179-185.

16. Fisher BE (1999) Most unwanted. Environ Health Perspect 107: A18-23.

17. Hagmar L, Lindén K, Nilsson A, Norrving B, Akesson B, et al. (1992) Cancer incidence and mortality among Swedish Baltic Sea fishermen. Scand J Work Environ Health 18: 217-224.

18. Svensson BG, Nilsson A, Jonsson E, Schütz A, Akesson B, et al. (1995) Fish consumption and exposure to persistent organochlorine compounds, mercury, selenium and methylamines among Swedish fishermen. Scand J Work Environ Health 21: 96-105

19. Asplund L, Svensson BG, Nilsson A, Eriksson U, Jansson B, et al. (1994) Polychlorinated biphenyls, 1,1,1-trichloro-2,2-bis(p-chlorophenyl)ethane ( $p, p^{\prime}-$ DDT) and 1,1-dichloro-2,2-bis(p-chlorophenyl)-ethylene (p,p'-DDE) in human plasma related to fish consumption. Arch Environ Health 49: 477-486.

20. Kramárová E, Stiller CA (1996) The international classification of childhood cancer. Int J Cancer 68: 759-765.

21. Dreifaldt AC, Carlberg M, Hardell L (2004) Increasing incidence rates of childhood malignant diseases in Sweden during the period 1960-1998. Eur J Cancer 40: 1351-1360.

22. Rothman K (2011) Episheet/Spreadsheets for the Analysis of Epidemiologic Data 2002.

23. Hjalmars U, Gustafsson G (1999) Higher risk for acute childhood lymphoblastic leukaemia in Swedish population centres 1973-94. Swedish Child Leukaemia Group. Br J Cancer 79: 30-33.

24. Mutanen P, Hemminki K (2001) Childhood cancer and parental occupation in the Swedish Family-Cancer Database. J Occup Environ Med 43: 952-958.

25. Knox EG (1994) Leukaemia clusters in childhood: geographical analysis in Britain. J Epidemiol Community Health 48: 369-376.

26. Leiss JK, Savitz DA (1995) Home pesticide use and childhood cancer: a casecontrol study. Am J Public Health 85: 249-252.

27. Infante-Rivard C, Sinnett D (1999) Preconceptional paternal exposure to pesticides and increased risk of childhood leukaemia. Lancet 354: 1819.

28. Infante-Rivard C, Labuda D, Krajinovic M, Sinnett D (1999) Risk of childhood leukemia associated with exposure to pesticides and with gene polymorphisms. Epidemiology 10: 481-487.

29. Buckley JD, Meadows AT, Kadin ME, Le Beau MM, Siegel S, et al. (2000) Pesticide exposures in children with non-Hodgkin lymphoma. Cancer 89: 2315 2321.

30. Hardell L, Eriksson M (2003) Is the decline of the increasing incidence of nonHodgkin lymphoma in Sweden and other countries a result of cancer preventive measures? Environ Health Perspect 111: 1704-1706.

31. Kerkvliet NI (2003) Immunotoxicity of Dioxins and Related Chemicals. In: Schecter A, Gasiewicz TA, (eds.) Dioxins and Health. (2ndedn), WileyInterscience: Hoboken, NJ, USA, 299-328.

32. Safe SH (1994) Polychlorinated biphenyls (PCBs): environmental impact biochemical and toxic responses, and implications for risk assessment. Crit Rev Toxicol 24: 87-149.

33. Svensson BG, Hallberg T, Nilsson A, Schütz A, Hagmar L (1994) Parameters of immunological competence in subjects with high consumption of fish 
Citation: Dreifaldt AC, Carlberg M, Hardell L (2013) Incidence Rates of Malignant Diseases in Childhood and Adolescence in Children to Swedish Fishermen. J Carcinog Mutagen 5: 153. doi:10.4172/2157-2518.1000153

Page 7 of 7

contaminated with persistent organochlorine compounds. Int Arch Occup Environ Health 65: 351-358

34. Bilrha H, Roy R, Moreau B, Belles-Isles M, Dewailly E, Ayotte P (2003) In vitro activation of cord blood mononuclear cells and cytokine production in a remote coastal population exposed to organochlorines and methyl mercury. Environ Health Perspect 111: 1952-1957.

35. Grimvall E, Rylander L, Nilsson-Ehle P, Nilsson U, Strömberg U, et al. (1997) Monitoring of polychlorinated biphenyls in human blood plasma: methodological developments and influence of age, lactation, and fish consumption. Arch Environ Contam Toxicol 32: 329-336.

36. National Food Agency Sweden (2012) Dioxin-och PCB-halter i fisk och andra livsmedel 2000-2011, In Swedish.

37. Hardell E, Carlberg M, Nordström M, van Bavel B (2010) Time trends of persistent organic pollutants in Sweden during 1993-2007 and relation to age, gender, body mass index, breast-feeding and parity. Sci Total Environ 408 4412-4419. 